\title{
The Effect of Eco-Centered Early Childhood Education by Seasonal Divisions on Child Nature-Friendly Attitudes and Emotional Intelligence
}

\author{
Jaeok Park ${ }^{1}$, Hyejin Jung ${ }^{2}$ \\ Department of Child Studies, Inha University, Incheon, Korea ${ }^{1}$ \\ Department of Family Happy Policy, Gyeonggido Family \& Women Research Institute, Suwon, Korea ${ }^{2}$

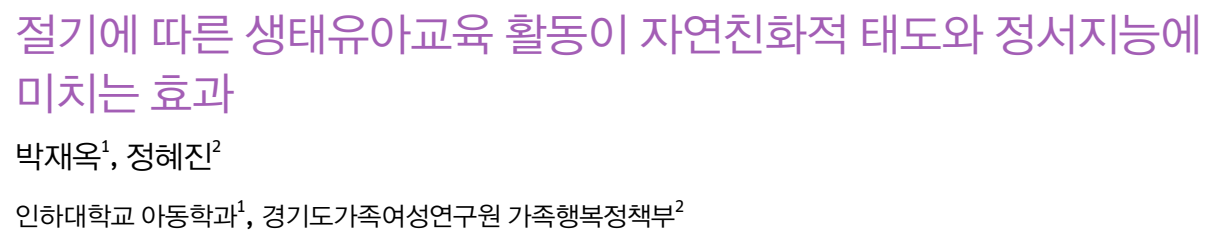

Objective: This study aimed to investigate how the eco-centered early childhood education by seasonal divisions influences the child's nature-friendly attitude and emotional intelligence.

Methods: Forty 5-year-olds from 2 preschools in Gyeonggi were selected through convenience sampling and were divided into the experimental group (21) and the comparative group (19). The experimental group received eco-centered childhood education by seasonal divisions 2 or 3 times a week (33 in total). Pre-post data were collected on both groups and analyzed via $t$-test and ANCOVAs.

Results: The key result was as follows: eco-centered childhood education by seasonal divisions influenced positively the nature-friendly attitude and emotional intelligence of children.

Conclusion: Based on the result, it is recommended that eco-centered early childhood education be applied in childhood education and that relevant program be developed. Eco-centered education by seasonal divisions is meaningful in early childhood so that children can be harmonious with the nature. Furthermore, the study should be continued for the development of qualified eco-centered education.

Keywords: seasonal divisions, eco-centered early childhood education, emotional intelligence, nature-friendly attitude

\section{서론}

도시화의 확산으로 교실 밖 자연 학습 환경은 유아들에게서 점차 멀어져 가고 있다. 유아기는 인간이 살아가는 동안 주변

Corresponding Author: Jaeok Park, Department of Child Studies, Inha University, 100 Inharo, Nam-gu Incheon 22212, Korea

E-mail: lilypjo@hanmail.net
환경과 자연 환경에 대해 가장 호기심이 많은 시기이며, 자기 중심성에서 점차 벗어나 자연 환경을 탐구하기에 가장 적합한 시기이다. 유아에게 있어 자연과의 직접적인 경험은 다양한 자연물과 관계를 형성하게 하고 자연이 주는 고마움과 생명

(C)The Korean Association of Child Studies

This is an Open Access article distributed under the terms of the Creative Commons Attribution Non-Commercial License (http:// creativecommons.org/licenses/by-nc/4.0) which permits unrestricted noncommercial use, distribution, and reproduction in any medium, provided the original work is properly cited. 
의 소중함, 자연과 더불어 살아갈 수 있는 친환경적 지식과 태 도를 배울 수 있는 기회가 될 수 있다. Laird, McFarland-Piazza 와 Allen (2014)은 인간들은 현재 살고 있는 자연의 자원들을 초월하여 더 나은 자원들을 얻기 위해 환경의 지속 가능성을 걱정하고 있으며, 이는 국제적인 관심사가 되고 있다고 하였 다. Campbell과 Jobling (2012)은 때문에 아이들은 자신들이 앞 으로 살아가야 할 자연환경에 대한 깊이 있는 교육이 필요하 다고 하였으나 여전히 많은 아이들은 자연환경으로부터 유리 된 경험을 하고 있다고 하였고, Chawla와 Cushing (2007)은 지 속가능한 자원을 찾는 방법을 모색하기 위해 유아기를 포함한 부모, 교육자 등 공동체의 자연환경에 대한 교육은 반드시 필 요하다고 하였다. An과 Jeon (2015)에 의하면, 유아기 동안 교 사와 또래들과 함께한 다양한 사회적 경험은 성인이 되었을 때 사고 형성에 많은 영향을 미칠 수 있으며, 특히 자연과 함께 했던 긍정적인 경험은 성인이 되어서 까지 지속되어 삶 전체 에 영향을 미칠 수 있기 때문에 또래, 교사와 함께 하는 자연활 동에 대한 교육적 접근이 필요하다. 따라서 유아교육을 담당 하는 사람은 유아에게 자연과 함께 하는 직접적 경험을 제공 함으로써 유아의 인지, 정서 발달에 매우 긍정적인 영향을 미 칠 수 있으므로 자연에 대한 바람직한 태도를 길러주기 위해 노력해야 한다(J. S. Han, 2003; M.-K. Kim, 2011).

생태유아교육은 급속한 도시화와 핵가족화 제도 아래 자 라고 있는 유아들에게 자연과 접할 기회를 제공하고, 정서적 안정감을 갖게 하고자 하는 목적으로 등장하였다(J.-T. Lim \& $\mathrm{Kim}, 2000)$. 생태유아교육은 유아와 자연이 하나이거나 유아 가 자연의 일부임을 강조하는 공동체 의식이 강한 측면이 있 어 생태계를 존중하고, 공동체로 여기는 교육방향으로 가야함 을 강조하고 있다. 우리나라는 2011년 산림교육 활성화에 관 한 법률(제10940호)이 시행되면서부터 생태유아교육에 대한 중요성과 인식이 확산되었으며, 유아교육과 관련된 교수, 연 구자, 어린이집 원장 및 교사, 학부모들이 교육과정에 있어 생 태유아교육에 대한 관심이 높아졌다(J.-S. Oh \& Bae, 2015).

Y. S. Lee (2007) 역시 자연환경의 파괴, 민족성 상실, 도시화 로 인한 농경사회의 붕괴, 전통문화의 소실과 우리나라의 생 태위기를 극복하고 전통적인 교육기반을 복원하기 위해 생태 유아교육이 도입되었다고 주장하고 있다. 생태유아교육 기관 담당자들이 세시풍속, 민속놀이 및 민요 등의 도입에 대해 절 실한 필요성을 느끼고 있으나 유아교육현장에서 생태유아교 육은 가시적인 활동의 결과물이 생성되지 않기 때문에 학부모 의 관심을 사기가 힘들며 생태교육을 표방하고 있더라도 실 제로는 유기농 먹거리 제공여부가 생태유아교육 실시기관 여
부를 판가름하는 기준이 되는 실태에 대해 우려를 표명하였다. Kweon (2010)은 생태유아교육 관점에서 유아교육환경에 대한 반성적 논의와 발전방안을 모색하였다. 유아는 오염된 실내교 육환경, 자연과 유리된 유아교육 환경 및 교재교구, 소비 지향적 놀이문화 환경에 당면해 있으며, 교사는 교재교구 제작과 행사 위주의 교육준비로 인한 업무과중, 유아교육기관의 경쟁으로 인한 교사의 외형능력 강조라는 현실에 당면해 있는 점에 대해 다양한 경험적 근거를 제시하여 주장하였고, 이러한 현실을 해 결하기 위한 방안으로 정제된 환경보다는 바깥놀이를 통해 유 아들이 자연에 있는 놀이감과 함께 호흡하고 살아가게 하고, 교 사는 자연적 환경을 구성하여 자연과 계절의 흐름에 맞게 교육 환경을 조성해야 하며, 교사와 유아뿐만 아니라 부모와 함께 하 는 동반자적인 교육공동체적인 관계를 형성을 제시하였다.

우리나라는 오랫동안 농사를 지으며 살아왔고, 농사는 모 든 생활에 근본이 되었으며, 태음력에 바탕을 두고 음력 정월 을 시작으로 하여 3 개월 단위로 봄, 여름, 가을, 겨울 사계절이 뚜렷한 농경사회였다. 농경의 주기는 절기의 주기와 맞물리는 생활의 주기이기도 하며, 세시풍속과 함께 전승되어져 왔다. Pyeon (2007)은 세시풍속이란 한국 사람답게 말하고 행동하고 느끼는 것을 삶으로 만나는 일이라고 정의하였다. 세시풍속은 1 년 12 달의 기상변화를 나타내는 우리나라의 24절기와 설, 추 석 등의 명절의 주기 중심으로 돌아간다. 세시풍속의 긍정적 목적은 풍요한 건강과 삶을 누리고자 하는데 있으며, 공동체 안에서 농사의 풍요를 기원하고 감사하며 복을 비는 의례놀 이, 식생활, 민간신앙 의식 등의 다양한 모습으로 전승되어 왔 다(J. E. Lee, 2008).

유아교육에 있어 세시풍속을 인식하게 된 것은 전통놀이, 전통음식 등 세부적인 영역으로 전통을 접근하다가 이를 모 두 포괄하는 개념을 발견하게 된 것이 계기가 되었기 때문이다 (Pyeon, 2007). 우리나라의 아이들은 자라날 때부터 한국말을 많이 사용하고, 음식, 놀이 등에 있어 전통적인 문화와 교육 내 용을 받아들이며 자라나야 한다. 그러나 현재 우리나라의 유아 들은 서구의 문화를 받아들이고 이른 시기부터 서양언어를 배 우는 등 우리 전통문화에 대한 이해가 우선시 되고 있지 않은 실정이다. 3-5세 누리과정에서는 창의.인성교육을 전통문화와 함께 특정 영역이 아닌 필요한 모든 영역에서 고루 다루도록 강조하고, 우리나라의 전통에 대한 이해와 자부심을 토대로 다 양한 나라, 인종, 문화를 편견없이 존중하고 관심을 갖는데 중 점을 두고 있지만 절기에 맞는 세시풍속을 중심으로 생태교육 활동을 하는 경우는 드물다. 따라서 우리의 전통과 사상에 의 해 아이들을 키우고, 자연에 대한 자연스러운 접근을 위해서는 
유아기 때부터 절기에 따른 세시풍속을 일상생활의 일부로 경 험시킬 수 있도록 하는 교육이 이루어질 필요가 있다.

Song (2016)은 자연친화적 태도란 인간과 자연이 함께 삶을 살아가면서 친숙하고, 자연과 하나 되어 가는 태도를 의미하 며, 특히 자연이라는 말에는 '스스로 그러한 존재’라는 뜻이 담 겨져 있어 원래의 상태, 순수한 상태로 있는 존재라는 의미를 갖고 있다고 하였다. H. S. Choi (2011)에 의하면 유아기는 인 간 형성의 결정적 시기로 이 때 형성된 가치, 습관 및 태도는 성 인이 된 후 삶에 큰 영향을 끼치게 되기 때문에 유아기에 경험 하는 자연에 대한 직접적인 체험은 자연에 대한 인식과 태도에 큰 영향을 미치게 되므로 이 시기에 올바른 태도와 가치를 함 양하도록 해야 한다고 주장하였다. 또한 H.-S. Cho (2005)는 유 아기 때부터 자연에 대한 경험은 유아가 자연과 인간과의 관계 를 어린 시기부터 체험하면서 자연에 대한 지적인 호기심을 넘 어 자연과 공존하는 삶의 태도를 형성하기 때문에 유아에게 자 연친화적인 태도를 형성해주기 위해서는 자연과의 접촉을 통 해 다양하고 계속적인 경험을 제공해 주는 것이 필요하다고 하 였다. 따라서 전통놀이 등과 같은 세시풍속이 포함된 절기에 따른 생태유아교육 활동을 통해 자연친화적 태도를 알아보는 것은 유아들이 동.식물에 대한 관심, 애호, 생명에 대한 존중의 식, 자연보호에 대한 인식을 알아보는데 중요한 지표가 될 수 있을 것이다.

유아교육현장에서의 자연친화적 교육은 유아들과 자연과 의 교감을 위해 자연을 직접 접하면서 체험할 수 있는 체험 프 로그램을 많이 시도하고 있다(E.-J. Cho, 2011; S.-A. Choi, 2010;

M.-K. Kim, 2011; Ryu, 2011; Ryu, Park, \& Lee, 2013; Yu, 2012). 그러나 이러한 자연체험 프로그램은 산책활동, 숲 체험 활동, 자연물 이용 등과 같이 한 가지에 특화된 활동이거나 활동을 함께 하는 대상이 교사와 또래로 이루어지는 경우가 대부분이 다. 보다 자연친화적인 교육 환경을 조성하고 체험적인 활동 이 되기 위해서는 놀이에 접목하고, 다양한 활동대상과 이루어 지는 생태체험 활동을 진행할 수 있어야 자연과의 교감, 타인 과의 긍정적인 관계로 확장시켜 나갈 수 있다. 세시풍속이 포 함되어 있는 절기에 따른 생태교육 활동 경험은 유아의 다양 한 호기심을 유발할 뿐만 아니라 인지 및 정서적인 발달을 이 룰 수 있을 것이라 예측되지만 현재까지 우리나라에서 이루어 진 생태교육 활동을 통해 유아의 정서지능에 긍정적인 결과를 나타낸 연구들은 (H. S. Choi, 2011; J.-J. Kim, 2009; S. H. Kim \& Park, 2014; J.-Y. Lee, 2015; S. M. Lee, 2012; E. J. Lim, 2013) 주로 텃밭 가꾸기, 산책하기, 생태그림책 등을 활용했을 뿐 우리나 라 절기와 세시풍속, 전래놀이가 절충된 프로그램을 활용한 연
구는 없었다.

현대사회 유아교육은 인지능력만을 강조하는 교육에서 개 인과 타인에게 감정이입과 희망을 키워주는 능력인 정서의 발 달을 함께 강조하는 풍토로 변화되고 있다. 정서지능은 인지 능력을 평가하는 $\mathrm{IQ}$ 와 다르게 보다 큰 만족을 위해 현재의 만 족감을 지연시킬 수 있으며, 충동적이기 보다는 이성적인 것 이 앞세우는 자질을 가진 속성이 있다. 정서지능이란 1990년 미국의 뉴햄프셔 대학의 John Mayer 교수와 Peter Salovery 교수 에 의해 처음 사용되었으며, 이들은 자신과 타인의 정서를 인 식하고 표현할 줄 아는 능력, 자신과 타인의 정서를 효과적으 로 규제할 줄 아는 능력, 자신의 삶을 계획하고 성취하기 위해 서 그런 정서를 이용하고 활용할 줄 아는 능력이라고 정의하였 다(H. Kim \& Lee, 2013). Goleman은 정서지능을 정서로 지각하 고 정서지능이 사람들에게 동기를 부여해 주고 절망적인 상황 에서 의욕을 잃지 않게 하며, 순간적인 만족을 지연시킬 수 있 게 하고, 기분을 조절하고 고뇌 때문에 사고능력이 방해를 받 지 않게 하고, 감정이입과 희망을 키워준다고 하였다(1995, as cited in S. H. Han, 2014). 최근 유아들은 바쁜 맞벌이 부모로 인 해 혼자 놀이하며 지내는 시간이 많으며, 스마트폰, 컴퓨터, TV 등의 개인 위주의 놀이에 몰입하게 된다. 특히 우리나라의 유 아들은 다른 나라의 유아들에 비해 놀이보다는 한글, 영어, 수 학 등의 조기학습과 관련된 활동의 비율이 높게 나타났다(K.-S. Lee \& Sohn, 2012). 이에 따라 유아의 발달단계에 맞는 정서지 능 발달에 어려움을 겪을 것으로 예측되는데 세시풍속에 포함 되는 전통놀이의 대부분은 2 명 이상의 사람들이 함께 할 수 있 고, 나눔, 배려, 협동 등의 가치를 포함하는 활동이기 때문에 정 서지능의 향상에 도움을 줄 수 있다(Jin \& Park, 2016). 또한 정 서지능은 $\mathrm{IQ}$ 와는 달리 후천적으로 학습되는 능력으로 가정과 교육기관에서의 활동을 통해 발달 또는 성숙이 가능하다. 따라 서 세시풍속이 포함된 절기에 따른 생태유아교육 활동이 유아 의 정서지능 발달에 긍정적인 영향을 미칠 것이라 예측되지만, 이에 대한 연구가 없어 구체적인 연구가 요구된다.

이에 본 연구는 절기에 따른 생태유아교육 활동이 유아의 정서지능 및 자연친화적 태도에 미치는 영향에 대해 분석해 보고자 한다. 또한 활동 경험 유무에 따라 어떠한 차이가 있는 지도 함께 검증해 보고자하며, 이를 위해 설정한 연구문제는 다음과 같다.

\section{연구문제 1}

절기에 따른 생태유아교육 활동 경험 유무에 따라 유아의 자 연친화적 태도에 차이가 있는가? 


\section{연구문제 2}

절기에 따른 생태유아교육 활동 경험 유무에 따라 유아의 정 서지능에 차이가 있는가?

\section{연구방법}

\section{연구대상}

본 연구의 대상은 경기도 $\mathrm{S}$ 시의 $\mathrm{G}$ 어린이집에 재원중인 만 5 세 반 21명이며, W기관에 재원 중인 만 5세반 19 명을 비교집단 으로 배정하였다. 연구대상 2 개의 집단은 생활수준이 비슷한 지역에 위치해 있는 국공립어린이집으로 비교집단은 남아 10 명, 여아 9명, 실험집단은 남아 12 명, 여아 9명으로 구성되었 다(Table 1). 실험집단의 평균연령은 남아 5년 4개월, 여아 5년 6 개월이며, 비교집단의 평균연령은 남아 5년 6개월, 여아 5년 5개월로 나타났다.

\section{연구도구}

\section{정서지능}

본 연구에서는 M. J. Kim (1998)이 개발한 '교사용 유아 정서 지능 평정척도'를 H. J. Kim (2008)의 연구에서 사용한 설문지 를 사용하였다. 정서지능 평정척도의 각 문항은 반대의 의미 를 가진 2개의 진술문으로 구성되어 있으며, 담임교사는 유아 와 함께 생활하면서 느낀 것에 기초하여 기록지에 표시를 한 다. 예를 들면 "감정을 나타내는 말과 얼굴표정이 일치한다." 와 “감정을 나타내는 말과 얼굴 표정이 일치하지 않는다.” 진 술문을 읽고, 해당 유아에게 평소 느끼는 것을 검사지의 번호 에 표시하게 된다. 정서지능 하위 범주는 6가지로 자기 정서 의 이용, 타인 정서의 인식 및 배려, 자기 정서의 인식 및 표현, 감정 조절 및 충동억제, 교사와의 관계, 또래와의 관계이며, 총
50 문항 (각 $12,10,9,9,5,5$ 문항)으로 검사시간은 유아 1 명당 평균 15 분정도가 소요되었다. 5점 Likert식 평정척도이며, 점 수가 높을수록 정서지능이 높음을 의미한다. 각 하위영역별 신뢰도 검증을 위해 Cronbach' $\alpha$ 계수를 산출하였고, 자기정서 의 이용 .88 , 타인정서의 인식 및 배려 .92 , 자기정서의 인식 및 표현 .89 , 감정조절 및 충동억제 .85 , 교사와의 관계 .87 , 또래 와의 관계 .90, 전체 신뢰도는 .91로 나타났다.

\section{자연친화적 태도}

본 연구에서 Musser와 Diamond (1999)가 제작한 CATES-PV (The Children's Attitudes Toward the Environment Scale-Preschool version)를 기초로 하여 Heo (2001)가 번안, 수정하고 So (2007) 가 일부 보완한 '자연친화적 태도 검사도구'를 사용하였다. 이 검사는 $1: 1$ 개인 면접 방식으로 다음의 순서로 검사한다. 먼저 유아는 담임교사로부터 자연친화적 태도의 각 문항마다 동일 한 상황에 대해 긍정적 태도와 부정적 태도를 보이는 상반되 는 두 분류의 이야기를 들은 후 어느 쪽이 유아 자신과 비슷한 지 선택하도록 한다. 예를 들면, 유아는 "이 친구는 기르고 있 는 동물의 집을 깨끗이 청소해 준다."와 “이 친구는 기르고 있 는 동물의 집이 더러워도 그냥 둔다.”와 관련된 그림을 보고 둘 중 자신과 비슷한 그림을 선택하게 된다. 선택 후 아주 많이 비슷한지, 비슷한지, 아주 조금 비슷한지에 대해 크기가 다른 3 개의 원모양을 선택하게 한다. 자연친화적인 태도의 그림을 선택하고, 가장 큰 원을 선택하면 6점, 중간원은 5점, 가장 작 은 원은 4점이며, 비자연친화적인 태도 그림을 선택하고, 작은 원을 선택하면 3점, 중간원은 2점, 큰 원은 1점으로 채점한다.

본 척도는 본래 동 - 식물에 대한 관심과 사랑, 생명에 대한 존중 의식, 인공적인 환경보다 자연환경 선호, 자연보호의 4 개 의 하위요소로 이루어졌으나, 신뢰도가 .50이하로 나타난 인 공적인 환경보다 자연환경 영역과 관련된 문항을 제외하고 분 석하였다. 따라서 동.식물에 대한 관심 8문항, 생명에 대한 존 중 의식 7 문항, 자연보호와 관련 질문 3 문항의 3 개 하위영역

Table 1

Study Participants

\begin{tabular}{|c|c|c|c|c|c|c|}
\hline \multirow[b]{2}{*}{ Group } & \multicolumn{2}{|r|}{ Boy } & \multicolumn{2}{|r|}{ Girl } & \multicolumn{2}{|r|}{ Total } \\
\hline & $n$ & Age & $n$ & Age & $n$ & Average age \\
\hline Experimental & 12 & 5 year and 6 months & 9 & 5 year and 5 months & 21 & 5 year and 6 months \\
\hline Total & 22 & 5 year and 5 months & 17 & 5 year and 6 months & 40 & 5 year and 6 months \\
\hline
\end{tabular}


의 총 18 개 문항만을 사용하였으며, 검사시간은 유아 1 명당 평균 20 분정도가 소요되었다. 각 하위영역별 신뢰도 검증을 위해 Cronbach' $\alpha$ 계수를 산출하였고, 동.식물에 대한 관심과 사랑 .86 , 생명에 대한 존중 의식 .83, 자연보호 .87, 전체 신뢰 도는 .89 이다.

\section{연구절차}

본 연구에서 실시한 절기에 따른 생태유아교육 활동은 절기에 따른 세시풍속 활동 내용으로 구성하여 2015년 5월 4일부터 7 월 24일까지 주2 또는 3회 총 33회로 실행되었다. 프로그램의 효과를 알아보기 위하여 사전검사(자연친화적 태도, 정서지 능)를 실시한 후 생태유아교육 활동 실시, 사후검사(자연친화 적 태도, 정서지능) 순으로 진행되었다. 실험처치 단계에서 실 험집단에 대해서는 절기에 따른 생태유아교육 활동을 실시하 고, 비교집단은 누리과정에 의거한 활동을 진행한 후, 자연친 화적 태도와 정서지능에 대한 사후검사를 실시하였다.

\section{교사교육}

실험집단의 교사는 교육경력 5년차로 3년제 유아교육학과를 졸업하였으며, 비교집단 교사는 교육경력 4년차로 4년제 아 동학과를 졸업한 교사이다. 연구도구의 측정 편차를 최소화하 기 위해 유아 정서지능과 자연친화적 태도를 측정하는 실험집 단과 비교집단의 담임교사에게 측정방법에 대한 사전교육을 실시하였다. 절기에 따른 생태 유아교육 활동을 실시하기에 앞서 실험집단의 교사를 대상으로 활동에 대한 교육을 3 회 1 시간씩 실시하였다.

\section{예비검사}

자연친화적 태도 검사도구에 대한 유아의 내용 이해 정도, 검 사 소요시간을 파악하기 위해 본 연구에 속하지 않는 경기도 S 시의 만 5 세 유아 10 명을 대상으로 예비검사를 실시하였다. 유 아들이 어려워하는 질문은 쉬운 말로 바꾸어서 질문을 사용하 였다. 자연친화적 태도의 응답반응에 대한 원의 크기를 3개로 분류해서 유아 자신과 비슷한 정도를 확연하게 구분하여 선택 할 수 있도록 도왔다.

\section{사전검사}

예비검사를 실시한 후 실험집단과 비교집단의 동질성을 확보
하기 위해 자연친화적 태도, 정서지능에 대한 사전검사를 실 시하였다. 자연친화적 태도 검사는 어린이집 내 독립된 조용 한 공간에서 실시하였으며 준비된 질문을 하고, 유아의 응답 에 따른 점수를 기록지에 작성하였다.

\section{프로그램의 구성 및 실시}

본 연구의 절기에 따른 생태유아교육 활동 프로그램은 유아 교육현장에서 5년 이상 생태놀이, 전래놀이 체험을 실시 경험 이 있는 원장 3 인 및 교사 2 인이 협력하여 만5세 유아에게 적 합한 형태의 33회 활동으로 구성하였으며, 이를 유아교육과 교수 1 인, 아동학 전공 박사 1 인에게 자문 및 검증을 받았다. Table 2 와 같이 전체적으로 이루어진 절기에 따른 생태유아교 육 활동을 제시하여 절기와 관련된 주제를 다양한 활동영역으 로 전개함으로써 유아들이 관련 활동을 다양하게 경험할 수 있도록 하였다.

프로그램은 첫째, 세시풍속과 민속놀이에 담겨 있는 조상 들의 삶을 통해 우리나라 고유의 세시풍속에 대해 관심을 갖 고 놀이를 즐길 수 있으며, 둘째, 우리 주변의 자연에 관심을 갖고 일상생활 속에서 이루어지는 생태교육을 경험할 수 있다 는 것으로 2 가지 목표를 설정하였다. 생태유아교육 활동 프로 그램의 주요 내용은 생태환경, 세시풍속, 전래놀이로 구성하 여 한 가지 활동에서 다양한 개념이 함께 다루어질 수 있다. 프 로그램 활동방법은 이야기 나누기, 게임, 동화, 음률, 미술 활 동 등이 통합적으로 활동할 수 있게 하였으며, 활동별로 교사, 또래, 부모, 조부모, 지역 어르신이 함께 할 수 있도록 대상을 포함하였다. 프로그램 활동에 사용된 교수매체는 사진, 동영 상, 실물, 동화책 등의 다양한 매체를 활용하였다. 실험집단에 게는 Figure 1 과 같은 활동안을 제시하였다.

\section{사후검사}

프로그램에 의한 생태유아교육 활동을 실시한 후 7월 27일부터 7월 31일까지 실험집단과 비교집단 유아들의 사후검사를 실시 하였다. 사후검사는 실험집단 21 명, 비교집단 19 명에게 사전검 사와 동일한 자연친화적 태도와 정서지능 검사를 실시하였다.

\section{자료분석}

본 연구는 자연친화적 태도, 정서지능의 사전검사 점수가 실 험집단과 비교집단 간 차이가 있는지 알아보기 위해 독립표본 


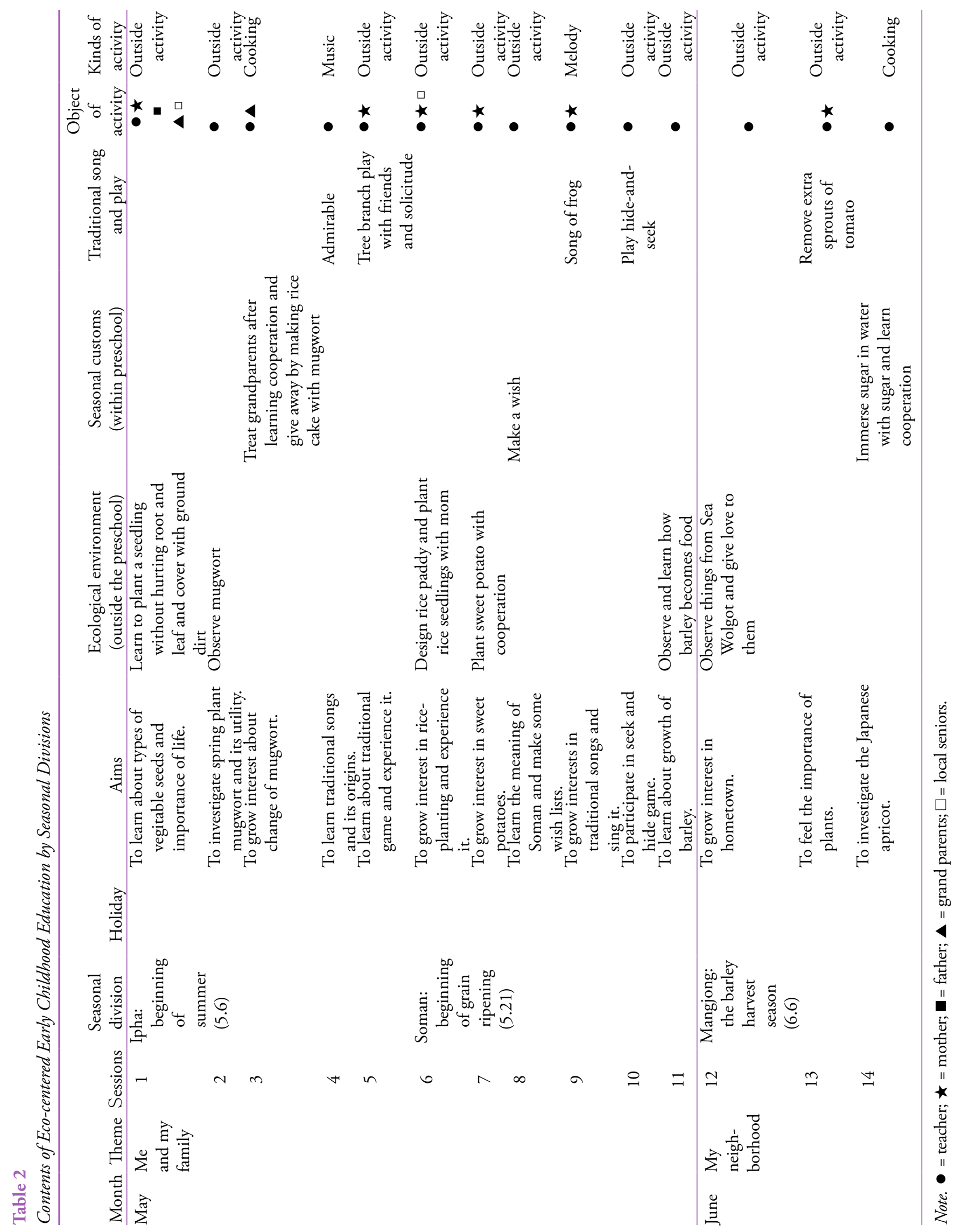




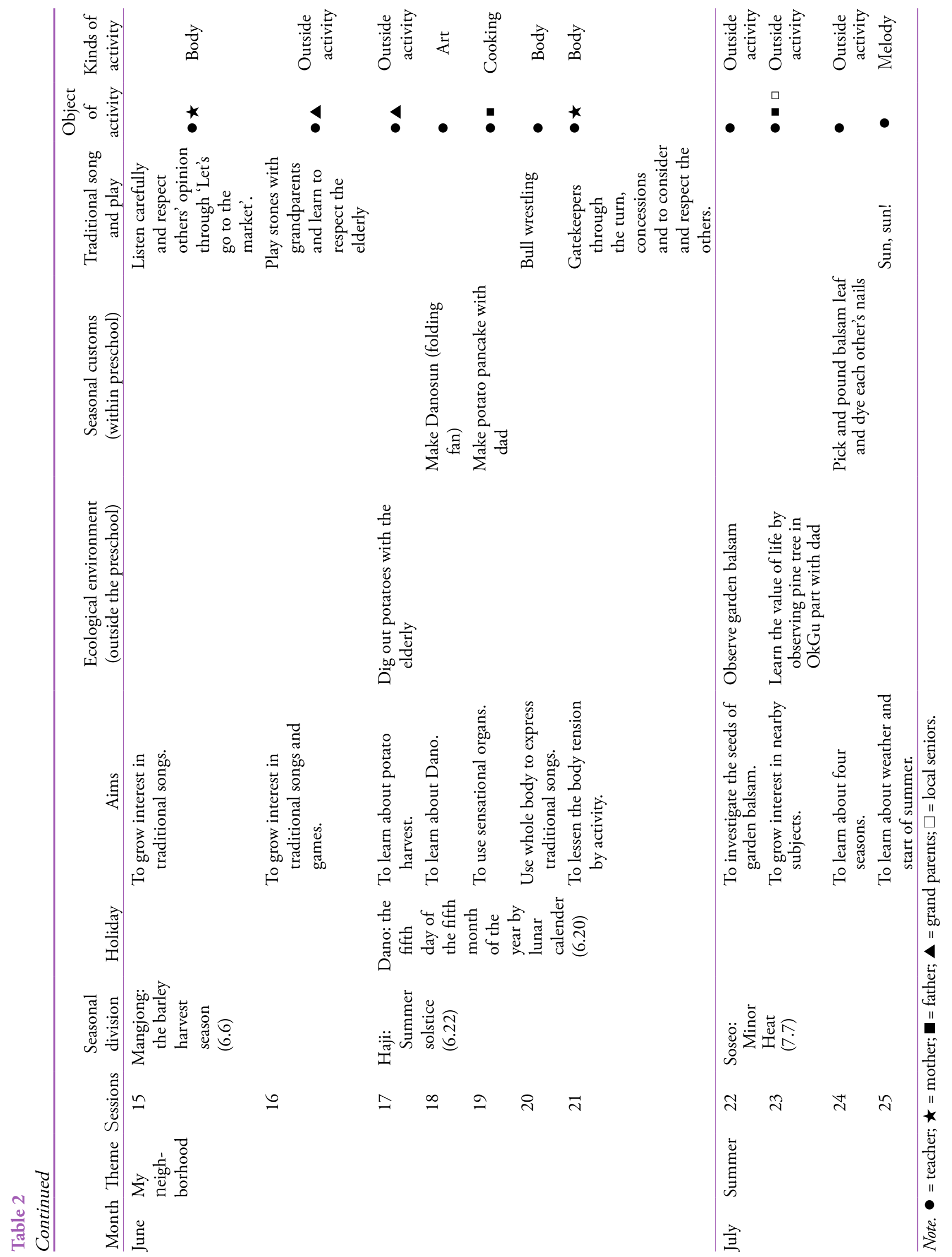




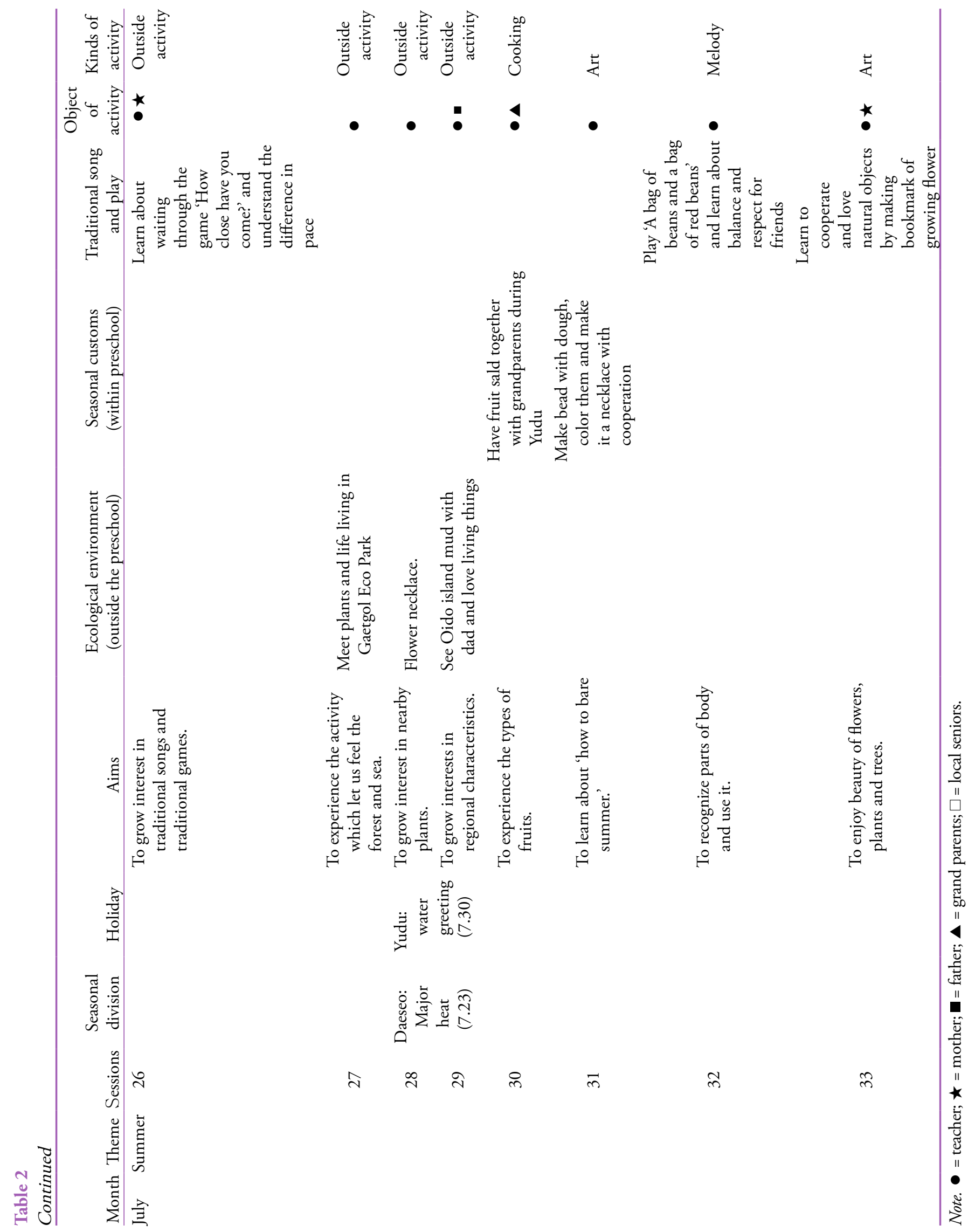




\begin{tabular}{|c|c|c|}
\hline $\begin{array}{l}\text { Seasonal } \\
\text { divisions } \\
\text { and } \\
\text { national } \\
\text { holidays }\end{array}$ & \multicolumn{2}{|c|}{$\begin{array}{l}\star \text { Yudu (Lunar calender } 6.15 \text {, Solar calender } 7.30 \text { ) - One of national holidays } \\
\text { Yudu is about beating the summer heat by washing hair with clean water and eating wheat noodles. On this } \\
\text { day, family gather and go to stream or waterfall, wash hair and body, and spend time together eating what } \\
\text { they brought. This is called Yudu festival in which people believed they can fight against disease and run } \\
\text { from summer heat in this way. }\end{array}$} \\
\hline $\begin{array}{l}\text { Name of the } \\
\text { activity }\end{array}$ & \multicolumn{2}{|c|}{ A bag of beans and a bag of red beans. } \\
\hline Objective & \multicolumn{2}{|l|}{$\begin{array}{l}\text { - Learn traditional play and song } \\
\text { - Learn to play controlling one's body } \\
\text { - Build positive relationship with a friend through play and learn about cooperation and solicitude }\end{array}$} \\
\hline Participants & \multicolumn{2}{|l|}{5 -year-olds and a teacher } \\
\hline $\begin{array}{l}\text { Relevant } \\
\text { factors } \\
\text { to Nuri } \\
\text { Curriculum }\end{array}$ & \multicolumn{2}{|c|}{$\begin{array}{l}\text { - Communication > Speaking: Feeling, thoughts, experience } \\
\text { - Exercise, Health> Body control and basic exercise: Body control } \\
\text { - Social relationship > Pay attention to the society > Understand Korea } \\
\text { - Social relationship > Living together with other people > Get along with friends: Be considerate to friends } \\
\text { when playing }\end{array}$} \\
\hline $\begin{array}{l}\text { Contents of } \\
\text { the activity }\end{array}$ & 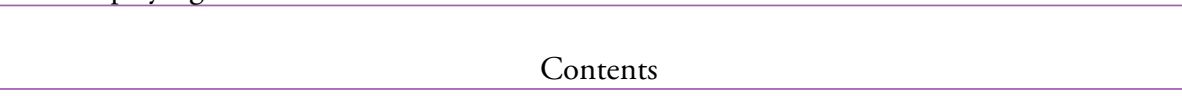 & Material \\
\hline & $\begin{array}{l}\text { <Introduction> } \\
\text { 1. Talk about milling (rice) in a mortar } \\
\text { T: (showing a mortar) Have you seen it? } \\
\text { T: Where did you see it? What's the name of it? } \\
\text { T: From very } \\
\text { (Pretending milling) Look carefully how milling in a mortar, and can you tell me about it? } \\
\text { <Development> } \\
\text { 2. Learn traditional play "A bag of beans and a bag of red beans" } \\
\text { T: Today, we are moving like a milling in a mortar. To play this game, we have to make a } \\
\text { pair of two friends. Who can come out and demonstrate in front of friends? }\end{array}$ & $\begin{array}{l}\text { Bang-a } \\
\text { lyrics board } \\
\text { music }\end{array}$ \\
\hline $\begin{array}{l}\text { Evaluation of } \\
\text { activity and } \\
\text { cautions }\end{array}$ & \multicolumn{2}{|c|}{$\begin{array}{l}\text { Teacher : By showing a mortar which reminds of traditional play "Kong-some pound pat-some pound", } \\
\text { children paid attention to the play and Korea. Children learned that they can play safely when they respect } \\
\text { friends so that they made it a play rule. Furthermore, it was a good opportunity to get along with friends } \\
\text { easily through simple traditional play in vast area with no material needed. } \\
\text { Child : It was fun to play carrying each other on one's back. It was a bit hard to carry a friend on my back } \\
\text { at first, but as I kept on doing it, I felt I gained more power and learned how to move. }\end{array}$} \\
\hline
\end{tabular}

Figure 1. An example of eco-friendly early childhood education by seasonal divisions (32 sessions). 
$t$-검증을 실시하였다. 집단 간의 오차를 최소화하기 위하기 위 해 실험 전에 실시한 사전검사 점수를 공변인으로 통제한 후, 사후검사 점수가 집단 간의 유의미한 차이를 나타내는지를 검 증하기 위하여 공변량 분석(ANCOVA)을 실시하였다.

\section{연구결과}

\section{자연친화적 태도 및 정서지능에 대한 사전검사}

실험집단과 비교집단의 사전검사 이후 두 집단이 동질적인지 확인하기 위한 $t$-검증 결과 자연친화적 태도의 하위요인 중 생 명에 대한 존중의식, 정서지능의 하위요인 중 자기정서의 이
용에서 집단 간 차이가 나타났다. 따라서 자연친화적 태도, 정 서지능에서 나타난 집단 간 차이를 비교하기 위해 사전검사를 공변인으로 통제하는 공변량분석을 실시하였다(Table 3).

\section{절기에 따른 생태유아교육 활동경험이 유아의 자연친화적 태도에 미치는 영향}

생태유아교육 활동경험의 적용 효과를 검증하기 위해 사전검 사 점수를 공변인으로 통제한 후, 사후검사 점수에 대한 공변 량분석(ANCOVA)을 실시하여 유아의 자연친화적 태도에 따 른 점수에 있어 집단 간 차이를 분석하였다. Table 4는 프로그 램의 활동경험에 따른 유아의 자연친화적 태도에 대한 집단별 사전 ·사후 검사 점수의 평균 및 표준편차, 조정된 사후검사

Table 3

Pretest Findings of Emotional Intelligence and Nature-Friendly Attitudes

\begin{tabular}{|c|c|c|c|c|c|}
\hline & \multicolumn{2}{|c|}{ Experimental group } & \multicolumn{2}{|c|}{ Comparative group } & \multirow[b]{2}{*}{$t$} \\
\hline & $M$ & $S D$ & $M$ & $S D$ & \\
\hline \multicolumn{6}{|l|}{ Nature-friendly attitude } \\
\hline Interest and love for animals and plants & 3.52 & 0.61 & 3.79 & 0.19 & 1.86 \\
\hline The level of respect for life & 3.37 & 0.66 & 3.81 & 0.17 & $2.98^{*}$ \\
\hline Protection of nature & 3.95 & 0.86 & 3.81 & 0.37 & -.68 \\
\hline \multicolumn{6}{|l|}{ Emotional Intelligence } \\
\hline Use of one’s emotion & 3.23 & 0.26 & 3.58 & 0.20 & $4.81^{* * *}$ \\
\hline Notice of other's emotion and understanding & 3.22 & 0.34 & 3.47 & 0.25 & 2.62 \\
\hline Notice of one's emotion and its expression & 3.40 & 0.34 & 3.68 & 0.23 & 2.97 \\
\hline Emotional and impulse control & 3.17 & 0.43 & 3.39 & 0.25 & 1.91 \\
\hline Relationship with a teacher & 3.45 & 0.37 & 3.61 & 0.28 & 1.55 \\
\hline
\end{tabular}

${ }^{*} p<.05 .{ }^{* * *} p<.001$.

Table 4

Mean and Standard Deviation of Subcategories of Nature-Friendly Attitudes

\begin{tabular}{|c|c|c|c|c|c|c|c|c|}
\hline \multirow[b]{2}{*}{ Subcategories } & \multirow[b]{2}{*}{ Group } & \multirow[b]{2}{*}{$n$} & \multicolumn{2}{|c|}{ Pre } & \multicolumn{2}{|c|}{ Post } & \multicolumn{2}{|c|}{ Adjusted score } \\
\hline & & & $M$ & $S D$ & $M$ & $S D$ & $M$ & $S E$ \\
\hline \multirow[t]{2}{*}{ Interest and love for animals and plants } & E & 21 & 3.52 & 0.61 & 4.73 & 1.17 & 4.87 & 0.19 \\
\hline & $\mathrm{C}$ & 19 & 3.79 & 0.19 & 4.07 & 0.67 & 3.92 & 0.19 \\
\hline \multirow[t]{2}{*}{ The level of respect for life } & E & 21 & 3.37 & 0.66 & 4.86 & 0.44 & 5.03 & 0.09 \\
\hline & $\mathrm{C}$ & 19 & 3.81 & 0.17 & 3.90 & 0.63 & 3.72 & 0.09 \\
\hline \multirow[t]{2}{*}{ Protection of nature } & E & 21 & 3.95 & 0.86 & 5.49 & 0.66 & 5.45 & 0.11 \\
\hline & $\mathrm{C}$ & 19 & 3.81 & 0.37 & 4.14 & 0.58 & 4.19 & 0.11 \\
\hline
\end{tabular}

Note. $N=40 . \mathrm{E}=$ experimental group; $\mathrm{C}=$ Comparative group. 
점수의 평균과 표준오차이다.

동 - 식물에 대한 관심과 애호의 집단별 사전 - 사후 검사 점 수의 평균을 살펴본 결과, 사전검사에서 비교집단 평균은 3.79 $(S D=0.19)$, 실헙집단 평균은 $3.52(S D=0.61)$ 으로 나타났으 나, 두 집단의 사전검사 점수를 공변인으로 한 조정된 사후검 사 점수에서는 비교집단 평균은 $3.92(S D=0.19)$, 실험집단 평 균은 $4.87(S D=0.19)$ 로 나타났다. 생명에 대한 존중의식에 서 두 집단의 사전검사 점수를 공변인으로 한 조정된 사후검 사 점수는 비교집단 평균이 $3.72(S D=0.09)$, 실험집단 평균은 $5.03(S D=0.09)$ 으로 나타났다. 자연호보에서 두 집단의 사전 검사 점수를 공변인으로 한 조정된 사후검사 점수는 비교집단 평균이 $3.92(S D=0.19)$, 실험집단 평균이 $4.87(S D=0.19)$ 로 나타났다.

본 활동의 경험 여부에 따라 실험집단과 비교집단의 자연 친화적 태도의 하위요인 점수 증가에 있어 집단 간 차이가 있 는지 알아보기 위해 사전검사 점수를 공변인으로 하고 사후검 사 점수를 종속변인으로 하여 공변량 분석을 한 결과는 Table 5과 같다.

Table 5에 제시되었듯이 동식물에 대한 관심과 애호에 대한 주효과는 $F=9.66$ ( $p$ <.001)로, 사전검사 점수를 통제한 두 집 단 간의 차이는 통계적으로 유의미한 차이가 있는 것으로 나 타났고, 생명에 대한 존중의식에 대한 주 효과는 $F=48.20$ ( $p$ <.001)로, 사전검사 점수를 통제한 두 집단 간의 차이는 통계 적으로 유의미한 차이가 있는 것으로 나타났다. 자연보호에 대한 주효과는 $F=51.45$ ( $p$ <.001)로, 사전검사 점수를 통제

Table 5

ANCOVA Results of Subcategories of Nature-Friendly Attitudes

\begin{tabular}{clrrrr}
\hline Subcategories & \multicolumn{1}{c}{ Source } & \multicolumn{1}{c}{$S S$} & $d f$ & \multicolumn{1}{c}{$M S$} & $F$ \\
\hline Interests and & ANCOVA (pre) & 9.28 & 1 & 9.28 & $9.66^{* * *}$ \\
$\begin{array}{c}\text { love for } \\
\text { animals and }\end{array}$ & Group & 8.26 & 1 & 8.26 & \\
plants & Error & 26.08 & 37 & 0.70 & \\
The level of & Total & 820.71 & 40 & & \\
respect for & Group & 5.36 & 1 & 5.36 & $48.20^{* * *}$ \\
life & Error & 5.59 & 37 & 0.15 & \\
& Total & 797.10 & 40 & & \\
Protection of & ANCOVA (pre) & 6.12 & 1 & 6.12 & $51.45^{* * *}$ \\
nature & Group & 15.78 & 1 & 15.78 & \\
& Error & 8.75 & 37 & 0.23 & \\
& Total & 974.00 & 40 & & \\
\hline
\end{tabular}

${ }^{* * *} p<.001$.
한 두 집단 간의 차이도 통계적으로 유의미한 차이가 있는 것 으로 나타났다. 따라서 본 활동이 자연친화적 태도의 하위요 소를 증진시키는데 효과적인 것으로 해석되어진다.

\section{절기에 따른 생태유아교육 활동경험이 유아의 정서지능에 미치는 영향}

생태유아교육 활동 경험의 적용 효과를 검증하기 위해 사전검 사 점수를 공변인으로 통제한 후 사후검사 점수에 대한 공변 량분석(ANCOVA)을 실시하여 유아의 정서지능에 따른 점수 에 있어 집단 간 차이를 분석하였다. Table 6 은 활동경험의 적 용에 따른 유아의 정서지능에 대한 집단별 사전 - 사후 검사 점 수의 평균 및 표준편차, 조정된 사후검사 점수의 평균과 표준 오차이다.

자기정서 이용의 집단별 사전.사후 검사 점수의 평균을 살 펴본 결과, 사전검사에서 비교집단 평균은 $3.58(S D=0.20)$, 실험집단 평균은 $3.23(S D=0.26)$ 으로 나타났으나 두 집단의 사전검사 점수를 공변인으로 한 조정된 사후검사 점수에서는 비교집단 평균이 $3.38(S D=0.05)$, 실험집단 평균은 $4.23(S D$ $=0.05)$ 으로 나타났다. 타인 정서의 인식 및 배려에서 두 집단 의 사전검사 점수를 공변인으로 한 조정된 사후검사 점수는 비교집단 평균이 $3.17(S D=0.05)$, 실험집단 평균이 $4.28(S D=$ 0.05)로 나타났다. 자기정서의 인식 및 표현에서 두 집단의 사 전검사 점수를 공변인으로 한 조정된 사후검사 점수는 비교집 단 평균이 $3.64(S D=0.09)$, 실험집단 평균이 $4.36(S D=0.09)$ 으로 나타났다. 감정 조절 및 충동억제에서 두 집단의 사전검 사 점수를 공변인으로 한 조정된 사후검사 점수는 비교집단 평균이 $3.34(S D=0.06)$, 실험집단 평균은 $4.20(S D=0.06)$ 으 로 나타났다. 교사와의 관계에서 두 집단의 사전검사 점수를 공변인으로 한 조정된 사후검사 점수는 비교집단 평균이 3.49 $(S D=0.06)$, 실험집단 평균이 $4.41(S D=0.06)$ 으로 나타났다. 또래와의 관계에서 두 집단의 사전검사 점수를 공변인으로 한 조정된 사후검사 점수는 비교집단 평균이 $3.19(S D=0.06)$, 실 험집단 평균이 $4.02(S D=0.06)$ 로 나타났다.

생태유아교육 활동의 경험 여부에 따라 실험집단과 비교집 단의 정서지능의 하위요인 점수 증가에 있어 집단 간에 차이 가 있는지 알아보기 위해 사전검사 점수를 공변인으로 하고 사후검사 점수를 종속변인으로 하여 공변량 분석을 한 결과는 Table 7과 같다.

Table 7에 제시되어 있듯이, 자기 정서의 이용에 대한 주효 과는 $F=64.97(p<.001)$ 로 사전검사 점수를 통제한 두 집단 
간의 차이는 통계적으로 유의미한 차이가 있는 것으로 나타 났다. 타인 정서의 인식 및 배려에 대한 주효과는 $F=106.68$ $(p<.001)$ 로 사전검사 점수를 통제한 두 집단 간의 차이는 통
계적으로 유의한 차이가 있는 것으로 나타났다. 자기 정서의 인식 및 표현에 대한 주효과는 $F=12.54(p<.001)$ 로 사전검 사 점수를 통제한 두 집단 간의 차이는 통계적으로 유의한 차

Table 6

Means and Standard of Subcategories of Emotional Intelligence

\begin{tabular}{|c|c|c|c|c|c|c|c|c|}
\hline \multirow[b]{2}{*}{ Subcategories } & \multirow[b]{2}{*}{ Group } & \multirow[b]{2}{*}{$n$} & \multicolumn{2}{|c|}{ Pre } & \multicolumn{2}{|c|}{ Post } & \multicolumn{2}{|c|}{ Adjusted score } \\
\hline & & & $M$ & $S D$ & $M$ & $S D$ & $M$ & $S E$ \\
\hline Use of one's emotion & $\mathrm{E}$ & 21 & 3.23 & 0.26 & 4.09 & 0.28 & 4.23 & 0.05 \\
\hline \multirow[t]{2}{*}{ Notice of other's emotion and understanding } & $\mathrm{E}$ & 21 & 3.22 & 0.34 & 4.16 & 0.41 & 4.28 & 0.05 \\
\hline & $\mathrm{C}$ & 19 & 3.47 & 0.25 & 3.32 & 0.39 & 3.17 & 0.05 \\
\hline \multirow[t]{2}{*}{ Emotional and impulse control } & $\mathrm{E}$ & 21 & 3.17 & 0.43 & 4.08 & 0.60 & 4.20 & 0.06 \\
\hline & $\mathrm{C}$ & 19 & 3.39 & 0.25 & 3.47 & 0.39 & 3.34 & 0.06 \\
\hline \multirow[t]{2}{*}{ Relationship with a teacher } & $\mathrm{E}$ & 21 & 3.45 & 0.37 & 4.33 & 0.45 & 4.41 & 0.06 \\
\hline & $\mathrm{C}$ & 19 & 3.61 & 0.28 & 3.58 & 0.39 & 3.49 & 0.06 \\
\hline
\end{tabular}

Note. $N=40 . \mathrm{E}=$ experimental group; $\mathrm{C}=$ Comparative group.

Table 7

ANCOVA Results of Subcategories of Emotional Intelligence

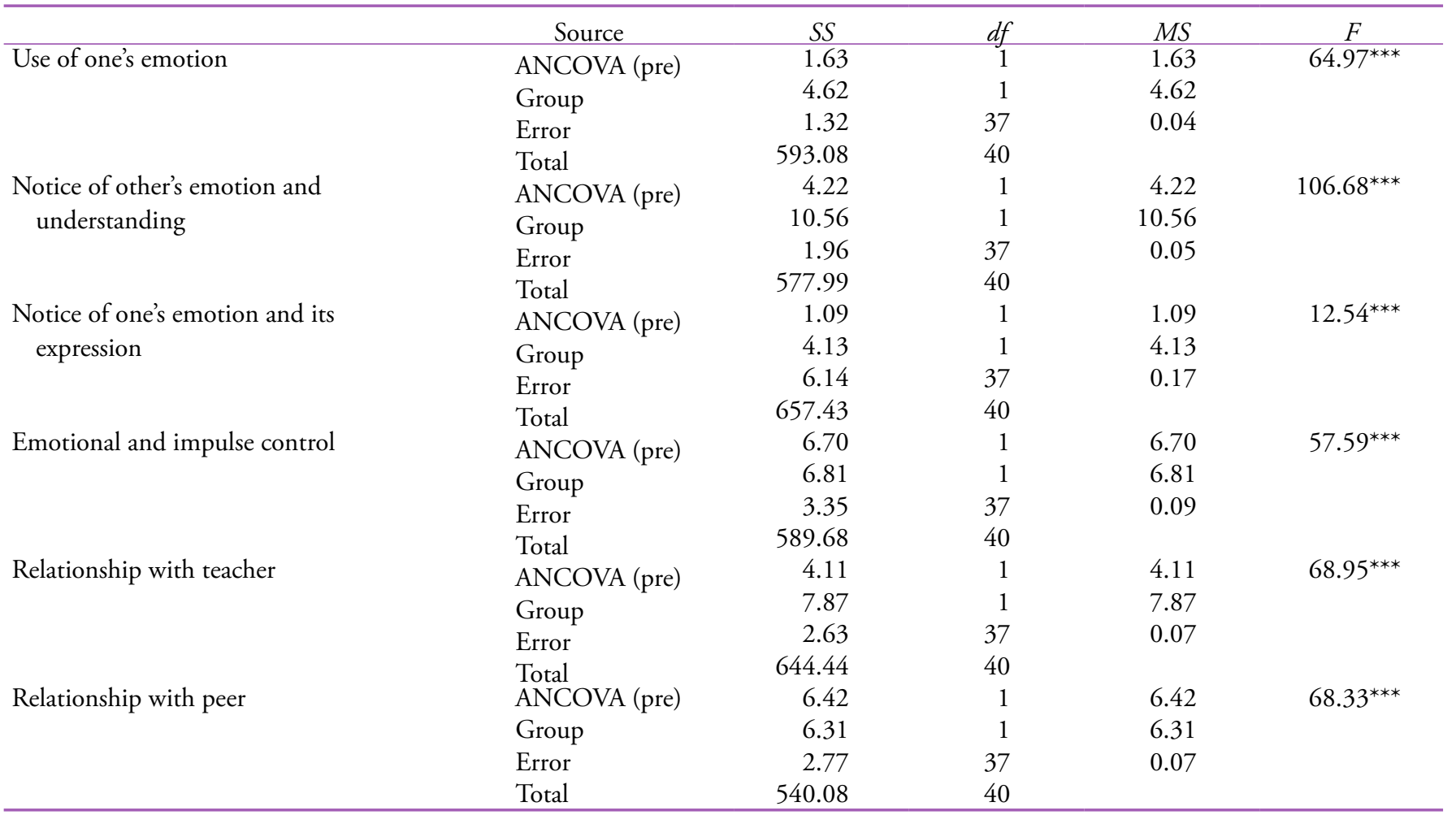

$\overline{* * *} p<.001$. 
이가 있는 것으로 나타났다. 감정 조절 및 충동억제에 대한 주 효과는 $F=64.97(p<.001)$ 로 사전검사 점수를 통제한 두 집 단 간의 차이는 통계적으로 유의한 차이가 있는 것으로 나타 났다. 교사와의 관계에 대한 주효과는 $F=68.95$ ( $p$ < .001)로 사전검사 점수를 통제한 두 집단 간의 차이는 통계적으로 유 의한 차이가 있는 것으로 나타났다. 또래와의 관계에 대한 주 효과는 $F=68.33(p<.001)$ 로 사전검사 점수를 통제한 두 집 단 간의 차이는 통계적으로 유의한 차이가 있는 것으로 나타 났다. 따라서 본 활동이 정서지능의 하위요소를 증진시키는데 효과적인 것으로 해석할 수 있다.

\section{논의 및 결론}

본 연구는 절기에 따른 생태유아교육 활동이 유아의 자연친화 적 태도와 정서지능에 미치는 영향에 대해 규명하는 것을 목 적으로 하였다. 본 연구에서 제기한 연구문제에 따른 주요 결 과를 요약하고 논의하면 다음과 같다.

첫째, 절기에 따른 생태유아교육 활동이 유아의 자연친화 적 태도에 미치는 영향을 알아본 결과, 유아의 자연친화적 태 도에서 집단 간 효과가 있는 것으로 나타났다. 이러한 결과는 생태유아교육 활동이 자연친화적 태도를 향상시킨다는 선행 연구 결과(Hwang, 2005; S.-H. Kim, 2015; S. H. Lee, 2013; E. J. $\mathrm{Lim}, 2013 ; \mathrm{H} .-\mathrm{J} . \mathrm{Oh}, 2008)$ 와 일치한다. 본 연구에서 실시한 활 동을 예로 들면, 5 월의 절기인 입하 때 교사는 유아들에게 봄 이 퇴색하고 여름이 시작한다는 절기의 의미와 함께 관련 음 식과 놀이 등에 대해 소개하고, 유아들에게 텃밭에 모종 심기, 쑥을 관찰하는 등의 자연관찰 경험을 하게 하였으며, 쑥으로 떡을 만들어 지역 어르신들께 대접하는 활동을 하는 등 자연 과 접하는 경험을 다양화 하여 절기를 이해할 수 있도록 하였 다. 이는 텃밭가꾸기와 연계한 요리활동을 통해 유아의 환경 친화적 태도 증진에 영향을 미친 연구(S.-K. Han, 2006; Jang, 2014)를 뒷받침해주는 결과라고 볼 수 있다. 본 활동을 통해 유아는 계절에 따라 자연의 변화를 관찰하고, 자연의 고마움 을 스스로 깨닫게 될 수 있게 되므로 절기에 따른 생태유아교 육 활동은 활동 과정에서 동물과 식물에 대한 애호, 생명에 대 한 존중의식, 자연을 보호하는 행동의 증가로 이어질 수 있는 활동임을 알 수 있다. 또한 날씨의 변화와 농경사회에서 조상 들의 지혜가 담긴 풍속들을 경험함으로써 자연물에 대한 감사 한 마음이 자연친화적 태도를 향상시키는데 기여한다는 점을 시사한다.
둘째, 절기에 따른 생태유아교육 활동이 유아의 정서지능 발달에 미치는 영향을 알아본 결과, 유아의 정서지능 발달에 도 집단 간 효과가 있는 것으로 나타났다. 이러한 결과는 생태 유아교육 활동이 유아의 정서지능 발달에 기여한다는 선행연 구 결과(H. S. Choi, 2011; G. A. Im, 2012; J.-J. Kim, 2009; S. H. Kim \& Park, 2014; J.-Y. Lee, 2015; S. M. Lee, 2012)와 일치 한다. 본 연구에서 실시한 활동을 예로 들면, 6 월의 절기 하지 때 교사는 유아들에게 태양이 가장 높게 있고, 길게 있는 시기 라는 절기의 의미와 함께 감자로 아빠와 전을 해먹는 활동(토 요아빠참여 활동), 지역 어르신들과 감자를 캐보는 활동을 경 험하게 하였으며, 친구들과 황소씨름, 문지기 놀이 등 신체활 동 놀이를 접할 수 있게 하는 등 유아가 또래, 부모, 어르신 등 다양한 사람들과 함께 활동하는 경험을 통해 절기를 이해하도 록 하였다. 이는 협동적 자연친화 활동 프로그램을 통해 또래 와의 상호작용하며 자신의 감정을 교류하고, 타인을 배려하 며, 자신의 역할 수행하는 기회를 갖는 등 정서를 활용하는 능 력이 향상되었다는 연구(Shin \& Kwon, 2014)와 생태체험활동 을 통해 타인을 인식하고 조절하는 능력이 향상되었다는 연구 (Suh, 2014)를 지지해 주는 결과라고 볼 수 있다. 이러한 결과 로 볼 때 절기에 따른 생태유아교육 활동은 활동 과정에서 교 사와 또래 또는 부모, 조부모, 지역 어르신과 함께 하는 상호작 용이 자연스럽게 이루어지기 때문에 유아의 정서적인 성장을 할 수 있도록 도와줄 수 있는 활동임을 알 수 있다. 특히 전래 놀이를 통해 규칙을 배우고, 자신의 기술을 인정받고, 친구 또 는 어른을 배려하는 등 자긍심 및 배려심을 갖게 되어 정서적 인 안정감을 느낄 수 있게 되었던 것으로 파악된다.

절기에 따른 생태유아교육 활동을 전개하다보면 텃밭활 동, 산책 등과 같은 체험활동이 함께 연계되어 시행될 수밖에 없다. 도시화로 인해 유아들이 살아가고 있는 공간이 인공적 이고 무미건조할 수 있지만 그 공간속에서 세시풍속 체험, 전 통놀이 및 민요 등의 활동을 제공한다면 생태유아교육에서 주장하는 자연을, 놀이를, 아이다움을 되찾아주는 유아교육 의 방향으로 전개되고, 유아의 전인적인 성장을 도와줄 수 있 을 것이다. 결론적으로 본 연구는 절기에 따른 생태유아교육 활동이 유아의 자연친화적 태도에 미치는 영향을 알아본 결 과 동식물에 대한 관심과 애호, 생명에 대한 존중 의식, 자연 보호 모두에서 사전검사보다 사후검사에서 유의하게 높은 것 으로 나타났다. 이러한 결과를 통해 절기에 따른 생태유아교 육 활동을 통해 유아의 자연친화적 태도에 효과가 있음을 알 수 있다. 또한 절기에 따른 생태유아교육 활동은 유아의 정서 지능에 미치는 영향을 알아본 결과 정서의 이용, 타인 정서의 
인식 및 배려, 자기 정서의 인식 및 표현, 감정 조절 및 충동억 제, 교사와의 관계, 또래와의 관계 모두에서도 사전검사 보다 사후검사에서 유의하게 높은 것으로 나타났다. 따라서 절기 에 따른 생태유아교육 활동이 유아의 정서지능 발달에 효과 가 있음을 알 수 있다. 그러므로 세시풍속이 포함된 절기에 따 른 생태유아교육 활동은 유아의 자연친화적 태도와 정서발달 에 긍정적인 영향을 미친다는 점을 시사한다. 또한 세시풍속 과 관련된 놀이가 포함된 절기에 따른 생태유아교육 활동이 유아교육기관의 교육과정 운영에 있어 적극적으로 반영해야 할 계기를 마련해 주고, 유아들의 놀이문화에 우리나라의 절 기에 따른 풍속과 놀이가 자연스럽게 스며들 수 있도록 도움 을 주는 기초자료를 제공하였다는데 그 의의가 있다.

본 연구는 연구대상 어린이집이 소재한 지역의 자연환경에 제한되었고, 관찰 자연 소재도 주변에서 쉽게 접할 수 있는 내 용으로 선정되었다. 유아들에게 자연과 공존하는 삶을 알아 가도록 하기 위해서는 주변의 자연물뿐만 아니라 계절에 따 라 다양한 동식물 등의 자연물을 접할 수 있는 기회를 제공하 는 것이 필요하다. 이를 위해서는 유아에게 다양한 자연체험 을 위한 교육공간이 마련되어야 하며 교육활동에서 지역사회 의 자원에 대한 활용방안을 적극적으로 모색할 필요가 있다. 이러한 여건이 갖추어졌어도 효과적인 활동이 되기 위해서는 유아들에게 자연에 대한 긍정적인 태도와 인식을 갖도록 교사 의 자연에 대한 지식과 개념 및 긍정적인 태도가 우선되어야 한다. 이를 위해서는 적극적인 지원과 교사의 신념, 태도 등 다 각적인 교육적 통찰을 고려하여 교육현장에서 이를 실천하고, 농촌, 어촌, 산촌, 환경복합도시, 환경 단순도시 등 유아의 활 동환경을 중심으로 생태교육의 지도 방향을 제시하고 복합 환 경 지역에서는 복합 활용을 통해 교사의 프로그램 개발을 지 원하는 연구 개발이 필요하다. 아울러 앞으로 자연과 유리된 유아들의 다양한 정서적 문제 및 행동의 문제를 개선하기 위 한 노력의 일환으로 유아의 발달 수준과 연령별 누리과정에 적합한 절기에 따른 생태유아교육 프로그램 및 활동방법을 개 발하기 위한 연구가 지속되어야할 것이다.

\section{Conflict of Interest}

No potential conflict of interest relevant to this article was reported.

\section{References}

\section{In English}

Campbell, C., \& Jobling, W. (2012). Effective science learing environments. In C. Campbell \& W. Jobling (Eds.), Science in early childhood (pp. 80-85). Cambridge University Press.

Chawla, L., \& Cushing, F. D. (2007). Education for strategic environmental behaviour. Environmental Education Research, 13(4), 437-452. doi:10.1080/13504620701581

Laird, S. G., McFarland-Piazza, L., \& Allen, S. (2014). Young children's opportunities for unstructured environmental exploration of nature: Links to adults' experiences in childhood. International Journal of Early Childhood Environmental Education, 2(1), 58-75.

\section{In Korean}

An, E.-J., \& Jeon, Y.-Y. (2015). The effect of group play activities through traditional children's songs on young children's prosocial behavior and aggression. Journal of Children's Literature and Education, 16(4), 223-245. Retrieved from http://www.riss.kr/link?id=A101743705

Cho, E.-J. (2011). Effects of the nature experience activities in the gorest on emotional intelligence and emotional creativeness of young children (Master's thesis). Retrieved from http://www. riss.kr/link?id=T12514105

Cho, H.-S. (2005). The development and evaluation of a nature friendly program for young children. Korean Journal of Early Childhood Education, 25(5), 343-366. Retrieved from http://www.riss.kr/link?id=A99534791

Choi, H. S. (2011). Effects of nature-griendly mathematics education on children's mathematical abilities (Master's thesis). Retrieved from http://www.riss.kr/link?id=T12565361

Choi, S.-A. (2010). The effect of nature meditation activities on preschool children's emotional intelligence and daily stress (Master's thesis). Retrieved fromhttp://www.riss.kr/ link?id=T11918789

Han, J. S. (2003). The educational meaning of nature experience activity at kindergarten (Master's thesis). Retrieved from http://www.riss.kr/link?id=T9085259

Han, S. H. (2014). Effects of children's emotional intelligence, maternal parenting behaviors, and teacher-child relationship on peer-competence (Master's thesis). Retrieved from http:// www.riss.kr/link?id=T13358931

Han, S.-K. (2006). The effects of cooking and backyard gardening activities on children's pro-environmental attitude and scientifie process skill (Master's thesis). Retrieved from 
http://www.riss.kr/link?id=T10791069

Hwang, G. M. (2005). An effect of nature-friendly educational program on young children's emotional intelligence (Master's thesis). Retrieved from http://www.riss.kr/ link? id=T12237844

Im, G. A. (2012). A study on the effects of the nature-friendly educational activities of the 'xploring nature through getting familiar with and communing with nature' approach on children's nature-friendly attitudes and scientific investigation skills (Master's thesis). Retrieved from http://www.riss.kr/ link?id=T12909039

Jang, J.-Y. (2014). The influence of cooking associated with backyard gardening activities on children's pro-environmental attitude and social competence (Master's thesis). Retrieved from http://www.riss.kr/link?id=T13482015

Jin, Y. M., \& Park, H. A. (2016). The effects of traditional group play on preschoolers' development of social skills and emotional intelligence. The Journal of Eco Early Childhood Education \& Care, 15(1), 215-242. Retrieved from http:// www.riss.kr/link?id=A101833315

Kim, H., \& Lee, S. (2013). The effects of childcare center teachers' job satisfaction and burnout on young children's emotional intelligence and social ability. Journal of Korean Council for Children \& Rights, 17(3), 369-391. Retrieved from http:// www.newnonmun.com $/$ article $=56854$

Kim, J.-J. (2009). A study on young children's curiosity and naturefriendly attitude shown through their nature experiential activities. Korean Journal of Children's Media, 8(2), 259278. Retrieved from http://www.riss.kr/link?id=A76539289

Kim, M.-K. (2011). Effects of nature friendly educational activities through a walk on young children's naturalist intelligence and emotional intelligence (Master's thesis). Retrieved from http://www.riss.kr/link?id=T12396480

Kim, S. H., \& Park, E. J. (2014). The influence of nature experience activities based on ecological picture books on both scientific research skills and natural friendly attitude for the children. Journal of Early Childhood Education o Educare Welfare, 18(1), 60-88. Retrieved from http://www. riss.kr/link?id=A99959571

Kim, S.-H. (2015). The effect of activity in nature on young children's emotional intelligence and nature friendly attitude (Master's thesis). Retrieved from http://www.riss.kr/ link?id=T13717433

Kim, H. J. (2008). The effect of ecological art education program with community on young children's emotional intelligence (Master's thesis). Retrieved from http://www.riss.kr/ link?id=T11383015

Kweon, M.-R. (2010). An investigative study on the early childhood education environment through the reflective discussion: On the view of eco early childhood education.
The Journal of Eco-Early Childhood Education, 9(4), 85-107. Retrieved from http://www.riss.kr/link?id=A100113906

Lee, J. E. (2008). $R$ \& D on seasonal Korean music of infants education program (Master's thesis). Retrieved from http:// www.riss.kr/link?id=T11229958

Lee, J.-Y. (2015). The effects of physical activity programs on the natural environment on the infant's basic motor skills and nature friendly attitude: Focused on the two years old age's classes (Master's thesis). Retrieved from http://www.riss.kr/ link?id=T13817802

Lee, K.-S., \& Sohn, S.-Y. (2012). A comparison of the daily lives of children in Korea, China, Japan and Taiwan. Korean Journal of Early Childhood Education, 32(2), 49-71. Retrieved from http://www.riss.kr/link?id=A99535322

Lee, S. H. (2013). Impact of using picture books eco-friendly nature activities to the infant's emotional intelligence and verbal creativity (Master's thesis). Retrieved from http://www.riss. $\mathrm{kr} /$ link?id=T13310503

Lee, S. M. (2012). Impact of natural-objects exploration activities on the nature-friendly attitude and drawing representation skills of preschoolers (Master's thesis). Retrieved from http://www. riss.kr/link?id=T12926892

Lee, Y. S. (2007). A discourse on the ecological folklore and development of eco-kid education: In the case of the education of season's custom in Gwangju \& Jeonnam eco-kid community. The Korean Folklore, 46(1), 43-74. Retrieved from http://www.riss.kr/link?id=A76249615

Lim, E. J. (2013). The effects of nature play activities through a walk on young children's emotional intelligence and playfulness (Master's thesis). Retrieved from http://www.riss.kr/ link?id=T13036660

Lim, J.-T., \& Kim, S.-O. (2000). Research on understandings of professors, directors, and teachers about ecology centered early childhood education. The Korea Association of Child Care and Education, 6, 1-20. Retrieved from http://www. riss.kr/link?id=A3022159

Oh, H.-J. (2008). Effect of nature based art activities on the emotional intelligence of young children: Focused on preschool children (Master's thesis). Retrieved from http://www.riss. $\mathrm{kr} /$ link?id=T11518995.

Oh, J.-S., \& Bae, J.-H. (2015). A comparative analysis of research trends in academic journals about environmental education and ecological education for young children. Korean Journal of Child Care and Education, 94, 21-44. Retrieved from http://www.riss.kr/link?id=A101196296

Pyeon, H.-M. (2007). Aspects of acceptance of traditional Customs by early childhood education institutions and going beyond limitations. The Korean Folklore, 46, 105-136. Retrieved from http://www.riss.kr/link?id=A76249617

Ryu, J.-M. (2011). Impact of play-in-nature activities on the 
emotional intelligence of preschoolers (Master's thesis). Retrieved from http://www.riss.kr/link?id=T12633860

Ryu, S.-H., Park, Y.-H., \& Lee, S.-W. (2013). The effects of gardening activities promoting nature-experience on young children's emotional intelligence and nature-friendly attitude. Korean Education Inquiry, 31(3), 1-20. Retrieved from http://www.earticle.net/Article.aspx?sn=204028

Shin, M.-J. \& Kwon, Y.-H. (2014). The effects of the cooperative nature-friendly activity program on child's peer competence and emotional intelligence. The Journal of Korea Open Assotiation for Early Childhood Education, 19(1), 427-449. Retrieved from http://www.riss.kr/link?id=A9994372

So, K. H. (2007). The effects of a nature experience activity program on children's nature friendly attitude and artistic expression ability (Master's thesis). Retrieved from http://www.riss.kr/ link? id=T11028013

Song, M.-H. (2016). The effect of mathematical storytelling activities using natural objectives on young children mathematical abilities and eco-friendly attitudes (Master's thesis). Retrieved from http://www.riss.kr/link?id=T14021498

Suh, H.-J. (2014). The effets of u-learning integrated eco experience activities on young children's environmental friendly attitudes and emotional intelligence. The Journal of Korea Open Association for Early Chilhood Education, 19(2), 447-472. Retrieved from http://www.riss.kr/ link?id=A100000281

Yu, H.-J. (2012). The effect of nature experience activities on children's emotional intelligence and social skills (Master's thesis) Retrieved from http://www.riss.kr/link?id=T12915658

Jaeok Park http://orcid.org/0000-0002-0638-6034

Hyejin Jung http://orcid.org/0000-0003-4558-4436

Received August 31, 2016

Revision received October 24, 2016

Accepted October 28, 2016 